\title{
Attitudes to medical ethics among British Muslim medical practitioners
}

\author{
Aminah Molloy Centre for the Study of Islam and Christian-Muslim Relations, Selly Oak, Birmingham
}

\begin{abstract}
Editor's note
Miss Molloy, a British Muslim and a trained nurse has been carrying out research for the Certificate in the Study of Islam at the Centre for the Study of Islam and Christian-Muslim relations. This paper is based on that research.

In collecting her evidence on attitudes to medical ethics Miss Molloy explores with her survey sample such topics as contraception, life support machines, transplants, resuscitation and euthanasia. As the number of participants in her survey is small it cannot be classed as being 'scientifically valid', but it does highlight many of the very painful dilemmas faced by British Muslim medical practitioners.
\end{abstract}

\section{Introduction}

In the Islamic tradition the search for standards of ethics has continually found its source in the Qur'an and in the Sunna of the Prophet (p.b.u.h.) as transmitted in the Hadith. This is as true for medical practice as for other branches of ethics.

As regards Qur'anic teaching, a few passages will suffice to exemplify the main principles. Paramount is the sanctity of life: '. . . it is $\mathrm{He}$ (God) who grants death and life'. (53:44) Another passage expands on this in the following words: 'Nor take life, which God has made sacred, except for just cause . . . let him not exceed bounds in the matter of taking life . . .'(17:33). This is generally understood to include suicide, while 'just cause', according to Yusuf Ali, refers to punishment for murder and so excludes practices such as euthanasia, or mercy-killing. Two verses previously, infanticide and, by implication, abortion is prohibited. Similarly by implication, resuscitation is permitted since the final outcome rests with God: 'Truly, He who gives life to the (dead) earth can surely give life to (men) who are dead. For He has power over all things'. (4I:39) Another passage has by some Muslims been understood to permit experimentation on animals: 'It is God Who made cattle that you may use them for riding and some for food; and there are (other) advantages in them for you; that you may through them attain to any need (that may be) in your hearts ... (40:79-80). Finally, the passage in $11: 117$ extolling firmness and patience in pain and adversity has relevance to the question of the use of drugs.

There is a fair amount of material in the Hadith literature of relevance most of it confirming and elaborating on the Qur'anic principles. Of particular interest, however, are a number of Hadith encouragififg the search for new remedies and treatment, typical of which is one quoted by al-Bukhari: 'No disease God created, but that He created its treatment'. (Book $7 \mathrm{~S}^{\mathrm{N}}$ ) ch. I).

During the first Islamic century the Hippocratic Oath was adopted because of its felt compatability wi î the Islamic ideals.

During the classical Islamic period these princip were worked out in detail, in particular as regards the behaviour of physicians towards their patients. There was a general readiness to use what drugs were avaibable for healing purposes, even the use of opium as anaesthetic. On the other hand, some quarters wege reluctant to seek out new drugs and remedies, a d there was a general abhorrence of dissection whether $8 f$ human or animal corpses.

\section{Muslims and contraception}

In the 2oth century the question which appears to hate engaged Muslims most is that of contraception. The are Hadith which can be interpreted both ways, agd the modern debate has strong arguments both for and against. But the particular concern over contraception is symptomatic of the more general concern over how to translate the principles of classical ethics into practical situation of modern medicine. New drugs, new technology and techniques and new administ tive structures all create possibilities for and pressutes on the individual medical practitioner which constantly challenge traditional attitudes.

In many Muslim countries there is a certain amount of protection against these challenges. Many of the newest technologies are simply not available because of their cost, so the question of, for example, transpla ts is largely irrelevant. Legislation prohibiting certän practices, for example abortion, offers some protection against the pressures which the institutional demands of large hospitals, career structures and administratifye interests might otherwise impose. In general, the cggcerns of most medical practitioners lie in the more basic and urgent problems of hygiene, undernourishmegt, infant mortality, etc. However, even where such pipotection does exist, the lure and pressure of wealth leags to illegal abortions and the availability of modegn, expensive operations for the rich.

In Western countries the pressures are so m greater and the protection so much less. Wide availaBility of expensive technology and drugs, health servises 
to pay for them, often rigid career structures within large, all-inclusive administrative entities, permissive legislation; all combine to create almost irresistible pressures on those who are hesitant about conforming. Many Christian doctors are confronted with serious ethical problems in this context, and to some extent the specific problems are very similar to those confronting Muslim doctors. However, beyond the specific points on which traditional Muslim medical ethics differ from Western Christian ones, Muslim medical practitioners face the additional problem that their principles would be expressed in Islamic terms - terms which are essentially alien to their working environment.

The tensions Muslim doctors are likely to face as a result of thus working in a European environment are probably being experienced most seriously in Britain, where medical professionals from India and Pakistan form a substantial part of the personnel of the Health Service. To gain an impression of how such persons are reacting to and coping with the realities, the survey which constitutes the central part of this paper was conducted among a small group of practitioners.

\section{The survey}

Selection of subjects for the survey was made from the telephone directory on the basis of common Muslim names, or on the basis of personal recommendations by friends and colleagues already helping with the survey.

Of the 20 subjects interviewed, eight were originally from Bangladesh; seven from Pakistan; two from Syria, one from India, one from Kenya and one from Britain. In all there were 17 men and three women.

Their present specialities in the medical field varied greatly. Six were general practitioners; five were ophthalmologists; two anaesthetists (one coupling this with general practice); one radiologist; one acupuncturist; one pathologist; one medical physicist; one obstetrician/gynaecologist; and one midwife/general nurse.

Basically the questions were relevant to all concerned, as a general training is necessary before specialising. However, one or two found some problems especially puzzling, because they are only apparently problems in this secular society and not in their own Islamic societies - for example abortion.

The issues were discussed with each of the subjects in interviews lasting up to four hours.

\section{LIFE}

In trying to decide and establish the beginning of life over half (12) said that it began at fertilisation; two doctors said it began at about 12 weeks gestation (of pregnancy) when the fetus resembles a human being; two said between 12 and 16 weeks when the heart starts; three said between 26 and 28 weeks when the various functions are co-ordinated enough for independent existence; and one said that he just did not know! It is significant that the two most involved with the beginnings of life, the obstetrician and the midwife considered that life begins at fertilisation/conception.
Two other very interesting points came out of this question, one regarding the soul and one regarding the burial of a dead fetus.

Many saw the soul as being innate, but one doctor claimed that there is an Hadith saying that the soul enters the fetus at 40 days; one said that the soul does not enter until the 28th week, offering no reason; and one said that the embryo is only a concept - that the existence in utero is but a unit of life, not a whole life and so 'murder' is impossible before birth.

Not all the doctors were asked regarding the burial of the miscarried embryo or fetus, as the point only arose half way through the survey. However, the problem is that, if after the point at which one believes life to begin this life then ceases to exist, should it not be given the full burial rites? In parts of Bangladesh and India all miscarriages receive a burial, even when the embryo only appears to be a clot of blood. Some doctors adhered to this practice; one or two thought burial was unnecessary before about 12 weeks when the fetus could be identified as being human; one said no to burial rights because the fetus is not treated as a dead person in other ways, for example regarding property rights. The majority that were asked, however, appeared to be satisfied with the situation as it is in Britain at the moment.

\section{ABORTION}

The next, and very big problem discussed was that of abortion. Various opinions expressed by a minority of the interviewees as to the justifications for and timing of abortion are such as have been presented in the debate generally for many years. Most would perform an abortion to save a mother's life, but only three would accept socio-economic reasons as valid. Against the latter argument, the majority quoted the Qur'an as saying that God will provide for our needs, so we should not concern ourselves. Four of the doctors felt that the amniocentesis test for fetal abnormalities is part of the knowledge given us by God and as such should be used to the advantage of mankind, that is, to abort gross abnormalities, so preventing them from living an unwholesome life and being a burden on society. The final decision would have to lie with the parents. This is a modern trend in the Islamic world, being a departure from the traditional Shari'a (Islamic Law) and its administrators, although of course the parents may base their decision on these.

Finally, there was a minority, but a very adamant minority, who claimed that there is no reason at all for abortions, not even the mother's ill-health. If God wishes to save or take the mother's and/or the baby's life, then it is up to Him. However, this does not imply fatalism, for it is the doctor's duty to do everything in his power to save both lives. One doctor even pointed out that accidents never happen, and that even if contraceptives are being used, for whatever reason, and these fail, then it is the Will of God and must be accepted.

Concerning this question in general doctors on the whole agreed that all depends on the individual case, 
and that two or three doctors, some said preferably Muslims, should consult and decide together.

\section{CONTRACEPTION}

The doctors were sharply divided on this question, but no one said that contraception could not be used in the case of the mother's ill-health, not even those who would not permit an abortion under these circumstances, for they claim that prevention is better than a 'cure' that they cannot agree with.

Half found that contraception was acceptable for any reason whatsoever, especially bearing in mind one's responsibilities to one's existing children, for as one doctor said, how can a person expect to attain Paradise because he did not use contraception, when he was unable to bring his children up properly on socioeconomic grounds?

The other half basically felt that jeopardy to the mother's health, if she became pregnant again, was the only ground for using contraception, although four did add socio-economic grounds as being ethically acceptable.

One doctor argued strongly against the validity of socio-economic grounds, condemning them for being too 'jelly-like'. He claimed that the world does have the resources, but that these are not being exploited and distributed properly; people do not take zakaat (obligatory almsgiving) seriously enough, and anyway, economies will not be improved through contraception alone.

There then follows the problem of which types of contraception are ethically acceptable. Half accepted any contraceptive as being permitted. Four could only argue to the use of coitus interruptus, advocating all the while that it is more self control that is needed. While accepting all other forms, one doctor disagreed with sterilisation because he saw it as abuse of the body. Two objected to the use of intrauterine devices as actually causing early abortions.

\section{DEATH}

The only common factor here was that all the doctors said they would wait between five and thirty minutes after deciding a person was dead before signing the death certificate, just in case there should be any sign of life. Besides this, the final decision would be made on the basis of varying combinations of factors such as complete cessation of brain or heart activity (if necessary backed by an EEG or ECG) as well as the more traditional indications. The main dividing factor among the doctors seems to be whether they regard the brain or heart as being the master organ of the body.

\section{RESUSCITATION}

Nine of the subjects believed that a person should always be given the chance of resuscitation, whatever their present or previous condition, for God will decide whether it is successful or not. One of this group said that even if the chance is as remote as a million to one the person should be given the chance.

One doctor felt that all except those with bad brain damage should be given the chance. Seven others said that resuscitation should be tried on all people except known terminal cases. Two of these felt that theoreti- $\overrightarrow{\vec{V}}$ cally all people should be given the chance, but also felt $\bar{\delta}$ that realistically it is inhumane and often physically impossible for those concerned actually to attempt to $\stackrel{5}{?}$ revive a severely-sick person whom they have seen? suffering for a period of time. Another doctor felt that while we should do our best for the person according to $\frac{\bar{m}}{\frac{D}{\alpha}}$ our knowledge, he would not personally attempt $\stackrel{\mathbb{D}}{\circ}$ resuscitation on a person whose heart had been stopped के for more than two minutes, and would also think twice if the person was over 50 years of age. Another doctor said that he would only attempt resuscitation if he was $\vec{\omega}$ fairly sure that, if successful, the life of the person would be worthwhile to the individual and society and $\bar{\nabla}$ not one of misery to either.

Finally, the acupuncturist declared that resuscita- $-\omega$ tion is never needed in Eastern medicine because it is so $\vec{\omega}$ complete, and that if a person dies clinically, then there $\subseteq$ is nothing more that can be done for him.

\section{LIFE-SUPPORT MACHINES}

Thirteen of the doctors believed that any machine $\frac{\mathbb{D}}{0}$ should be used to assist life, but that when complete $\frac{\mathbb{D}}{3}$ brain death had occurred it should be turned off. One also added that the law of the land should be taken into consideration, and one other said that 20 minutes $\oplus$ should be allowed after brain death had been asces-. tained.

One doctor maintained that actual brain death is not necessary, but that the machine should be turned off on those suffering from severe brain damage, since to prolong such a life would be cruel to the patient and of $\stackrel{\mathbb{Q}}{\mathbb{Q}}$ no use to society.

Two said that they would turn the machine off when all the other signs of physical death were present, not $\vec{T}$ necessarily awaiting the cessation of brain functions. One pointed out that 'the love of those around is a cementing factor' guarding against the machines being $\widetilde{\Phi}_{\overparen{D}}$ turned off before ethically acceptable.

Two more claimed that no machine should ever be turned off, even in brain death, as we never really know $\delta$ the complete physical, chemical and mental condition

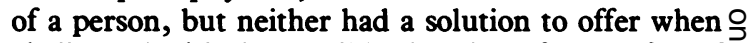
challenged with the possible situation of wards full of $>$ 'bodies' on life-supporting machines which are never to be turned off!

The acupuncturist said that he never has the need to 0 use such machines, because with the proper use of the $N$ pulse, philosophy and logic, more can be done for a N person than would ever be possible with the use of machines.

\section{TRANSPLANTS}

All the doctors, except one, agreed with the use of transplants to improve or maintain life, because theyo see the ability to transplant as God-given knowledge, which takes priority over any feelings of abuse to the bodies concerned. However, the one exception did $\frac{\varrho}{\sigma}$ maintain that respect of the body takes priority over 
such progress, although he himself has to be involved with ophthalmic transplants against his better judgement.

All 19 agreed that if the life of the donor is in question at all, then everything must be done to preserve and maintain this life, as it is as sacred as the one awaiting transplant. Several saw the donors as getting a special blessing from God for their selfless generosity; two said that trivial or cosmetic transplants are unethical; one said that although he sees their value he would not personally get involved with transplants; a couple said that only those with a very high success rate should be undertaken to avoid surgeons playing with life; and one pointed out that Islam does not say that we cannot share our bodies with others, but rather gives us great scope for self-sacrifice, and since it is everyone's duty to maintain life, if possible, to be a donor or a recipient is praiseworthy.

\section{HUMAN RESEARCH}

Is human research ethical in the light of the fact that Islam requires a person to be buried with the proper cleansing and prayers (janazah), between the next sunrise and sunset, and that the body is regarded as sacred and must be treated with respect?

Fifteen agreed that it is God's Will that medical research takes place, but emphasised that the body must be treated with respect, the research takes place in the Name of God, and that as proper a janazah as possible be given when the research is completed. One respondent would not give his body for research in a non-Muslim state, and a number of others stressed that the balance between progress and basic Islamic ethical responsibilities was very much on their conscience.

Of the remaining five doctors, one said that research is not necessary in Eastern medicine, as it is perfect, and the other four were in somewhat of a dilemma, not knowing what was right, but definitely not willing to give their own bodies for research.

\section{ANIMAL RESEARCH}

Of the 16 asked, one had no idea on the matter, but the other 15 basically agreed to the use of animals for research, because man's life takes priority and God has given man the use of animals for his own ends. However, great emphasis was laid on the fact that only experiments necessary to improve or save life should be carried out, (therefore not such things as cosmetic production), and that it is the duty of the experimenter to ensure that it is as painless and humane as possible.

\section{EUTHANASIA}

Seventeen said that they would never condone or practice euthanasia, for life is given by God and can only rightly be terminated by Him. They agreed that everything possible should be done to alleviate the sufferings of the patient, and one pointed out that we are not judges of the future. Others said how sympathetic and disturbed they become in extreme cases, one admitting that this may one day drive him to practise euthanasia.

As regards the omission of treatment which, if administered, might have allowed the patient to live longer, the majority (16) were quite definite that the patient should be treated and given the chance. How ever, one pointed out that he would not go to extremes with someone who had little chance.

Only one doctor said that he would definitely us negative euthanasia in any case where conditions ind $t^{+}$ cated that, if treatment were given, the result would not be a wholesome, useful life.

\section{DRUGS}

In very close conjunction with the problem of euthanasia is that of the use of dual-action drugs such as morphine.

Nine said that the control of pain was their priority and they would relieve this, although they would nof necessarily give large quantities of the drug. Howeveg two of these doctors did say that if substantial doses $\dot{\alpha}$ morphine were necessary to control a person's suffe $\dot{E}$ ing and misery, then they would give one lethal dose and not indulge in what they saw as a long, drawn-out euthanasia, which can take days or weeks. Another of these doctors also pointed out that God created mom phine, so why should we not use it?

Five more of my sample were not keen to use mo phine at all, but said that they would as a last resort, कf all else had failed.

Three were against the use of morphine under $8 \mathrm{ng}$ circumstances, believing that there are other means of making a person comfortable, and that a doctor prescribes morphine for a person is prescribun euthanasia. One of these said that in extreme cases would give an epidural anaesthetic to numb the patie and therefore render him painfree.

\section{ASSISTED SUICIDE}

Related to the two previous issues is that of assiste suicide, by the prescription of lethal drugs for someone to use on a person who is near and dear, with that person's permission, because of unbearable suffering on the part of the patient.

Seventeen said that they would definitely not pre: scribe such medicine, although several stressed that they would be very sympathetic. One or two admitted that they would not know what to do personally if their wives were desperately ill, suffering greatly, and ask for it all to be ended. A good number were emphatît that the person should be admitted to hospital, and thi all the parties concerned must be given all the supporo tive help necessary.

'Should a person become a pick-pocket in order t్ర help others?' asked one doctor; another pointed outt that God gives pain and death in His own time, which must be accepted by us; while another said: 'Optimg out deprives a person of psychological experiences ${ }^{5}$

\section{IS EUROPEAN MEDICINE ETHICAL?}

This very broad question of medical ethics evolvef from the survey when interviewing the acupuncturist who claimed that all those involved in European medicine are unethical and use unethical practices, as 
mentioned before. I therefore asked the remaining 17 of my sample to respond to this criticism.

Fourteen defended European medicine on the grounds that it is making great progress for the good of mankind, for the Qur'an says: 'engage your knowledge and find out'. Many saw that the successes far outweighed the failures, and that even the failures were not completely so, as much was learnt from them. One saw experiments as 'a response to the need to secure health', while two others said that if European doctors were being completely honest and ethical then they would include acupuncture and homoeopathy in their own practices.

Two of the sample saw a large part of European medicine as ethical, but believe that a staggering number of those involved are totally unethical, especially general practitioners (neither of them being such themselves), many of whom omit treatment and are not bothered to help patients day after day, finding repeat prescriptions, without seeing the patient for years sometimes, all for an easier way of living.

One doctor actually agreed with the criticism to a large extent, for in the East a person is treated as a whole being - physical, mental, emotional, spiritual and because there is no experimenting there are no side-effects.

\section{Views from two imams}

Having interviewed the medical practitioners, it was felt to be of interest to discover what imams, religious leaders, thought of the same questions. Two imams were interviewed. Neither had any special medical knowledge and so the problems and implications of each subject were first explained in great detail.

One believed that life begins at birth, although the soul enters the body at about 16 weeks' gestation; while the other saw life as an ongoing process, the sperm and ovum both being live cells even before the fusion. For the individual, life begins at fertilisation, but the entering of the soul is a controversial topic, believed by him to take place somewhere between 40 days and four months.

Both imams agreed that abortion is permissible in cases of severe risk to the mother's life, as one should not risk the loss of two lives. Contraception produced opposite views from the imams. The Sunni felt that it was not to be used at all, except in the case of chronic ill-health in the mother, whereas the other said that all types of contraception are permitted that do not cause harm to the users.

Both agreed that a person cannot be pronounced dead, and therefore buried, until there is absolutely no hope of resuscitation. As non-medical men they themselves would use rigor mortis as the deciding factor. Consequently, resuscitation and life-support mechanisms should be tried until death has definitely been established.

One imam said that only the transplant of blood is permissible, as this has no effect on the donor and is not regarded as abuse. No other transplants are allowed because the body is sacred and not to be mutilated. The other agreed about the blood, adding that a live donor $m$ may donate any part of his body for any type of transplant. However, he has reservations concerning the use $\bar{\AA}$ of parts of a dead body, for a dead body does not belong to anyone, so who can give permission? Perhaps it is acceptable if the person has left a will, but he person-O ally would not advocate such practices.

Neither imam could see any reason or excuse for any $\frac{\overline{\bar{s}}}{\vec{b}}$ form of hastening death for life is God's to give and take $e^{\mathbb{D}}$ as He pleases, not man's.

As regards research on living beings one said that it is allowed to a limited extent when the animals are alive, avoiding pain at all costs, but not when the animal is $\vec{\omega}$ dead as this is disrespectful. The Shi'i pointed out thate animals have been created by God for man's use, bus should only be used in experiments dealing with lifesaving and prolonging conditions.

\section{Conclusion}

The number of medical practitioners interviewed and the method of their selection make it clear that noss 'scientifically valid' conclusions can be drawn from the्] survey. Neither can any assumptions be made as to the relation between the views of Muslim medical pract titioners and those of religious scholars. What can be drawn out of the above summary of the interviewso conducted is the dilemma, often a very painfog dilemma, in which many of those individuals fing themselves when faced with a choice between cons ence and standard practice. There is clearly a tension between what the 'system' suggests they do on the one hand and, on the other, what they would like to dō and/or what they feel they ought to do as Muslims Their decision is made no easier by the fact that mose have been trained in ways which explicitly and implicitly are European and non-Muslim in assump tion and orientation.

What does a Muslim doctor do in such a situation He could, of course leave his religious beliefs at home:so to speak, but this is a solution which may only offe $\bar{B}$. short term relief, and one which many Christian doci tors are finding increasingly difficult to bear. The option of resignation, of leaving the profession, is on which has been adopted by a few individuals. But that still leaves the majority with the basic dilemma. Fot these, the question of what is ethically acceptable med ical practice has not been satisfactorily answered. Tho classical principles are insufficient in the context of what is possible in today's medical world. Most Must lims would agree that what is needed is a serious new look at the Qur'an and Hadith, but it is unfortunate that much of what is being pronounced in this field b Muslim thinkers today seems to show little or no awareness of the practical situation or the medically possible.

There is more potential at the moment in the exisp tence of national associations of Muslim medical prae titioners which could play a very important part i bringing the issues of the profession's ethics more inte 
the open and thus provide a necessary support to many of their colleagues. Additionally, however, it should not be forgotten that Muslims are not alone in confronting these issues. Many Christians and nonChristians have serious doubts about some of the trends in modern medicine. Surely, this is an area where nobody can work satisfactorily within the confines of sectional interests, an area which by its very nature calls for openness and common cause to be made across the boundaries of religious differences.

\section{Select bibliography}

Badry, Malik D (1979) The dilemma of Muslim psychologists. London: MWH London Publishers.
Hamarneh, S (1970). Medical education and practice in medieval Islam, The history of medical education. Berk-으 ley: University of California Press.

Levy, M (1967). Medical ethics of medieval Islam, with special reference to al-Ruhawi's practical ethics of the? physician. Transactions of the American Philosophical Society, 57 (new series), pt 3.

Mawdudi, A A (1974). Birth control. Karachi: Islamic Publications.

Meyerhof, $M$ (1937). Science and medicine, in Arnold ands Guillaume (eds), The legacy of Islam. Oxford: Clarendon $\mathbb{D}$ Press, pp 31 I-355.

Ullman, M (1978). Islamic medicine. Edinburgh: Edinburgh University Press.

Wasty, N H (1962). Muslim contribution to medicine. Lahore: $\overrightarrow{-}$ Avicenna Society. 